\title{
QUALITY CONTROL OF CHINESE VELVET ANTLER BY PROFILING OF PESTICIDE RESIDUES AND HEAVY METALS
}

\author{
ZHANG, Z. Y. ${ }^{1}-$ LIU, X. F. ${ }^{2}-$ HoU, Y. T. ${ }^{1}-$ WANG, R. R. ${ }^{1}-$ LI, P. F. ${ }^{1}-$ ZHAO, C. W. ${ }^{3 *}$ \\ ${ }^{I}$ School of Life Science and Medicine, Dalian University of Technology, DaGong Road, Panjin \\ Liaoning 124221, China \\ ${ }^{2}$ Department of Laboratory Medicine, Jilin Cancer Hospital, HuGuang Road, Changchun Jilin \\ 130021, China \\ ${ }^{3}$ Department of Orthopedics, Affiliated Hospital of Changchun University of Chinese Medicine, \\ GongNong Road, Changchun Jilin 130021, China \\ *Corresponding author \\ e-mail: zcw_1980@126.com; phone: +86-135-9608-8558; fax: +86-431-8617-7151
}

(Received $1^{\text {st }}$ Mar 2019; accepted $21^{\text {st }}$ May 2019)

\begin{abstract}
Quality control is the most critical issue for Chinese medicines (CMs) as its increasing acceptance all around the world. This study measure and analyse the pollution of nine kinds of velvet antlers, which is one of the classical Chinese medicines, in different species and parts of Cervus Nippon and Cervus Elaphus in China. Following the relevant Chinese national standards to evaluate the pollution, we employed the Quick Easy Cheap Effective Rugged and Safe multiresidue method (QuEChERS), combinating with gas chromatography (GC), for the analysis of the organochlorine pesticides (OCPs) in velvet antler. The Inductively Coupled Plasma Mass Spectrometry (ICP-MS) method was used to detect lead, cadmium, copper and arsenic in nine kinds of velvet antlers. The content of mercury and the pollutants in the nine kinds of velvet antlers were all in line with the Chinese Pharmacopoeia. However, these results showed that velvet antler as the unique animal medicine also has a certain amount of pesticide residues, and the individual detection indicators in antler, such as heavy metal copper, are high, which suggests that, we still need to conduct reasonable testing and analysis of heavy metals and pesticide residues in velvet antler before giving it to patients to ensure the safety of clinical application.

Keywords: organochlorine pesticides, heavy metal, Chinese medicines, medication safety
\end{abstract}

\section{Introduction}

Traditional Chinese medicine (TCM) is one of the important components of the traditional medicine in the world. Chinese medicinal materials are rich and widely distributed in China. The Chinese medicinal materials have been accepted by the vast majority of patients because of the characteristics of mild pharmacology, specimens and treatment, persistent drug effects and small side effects (Huie, 2002). With a growing number of reports announcing that excessive heavy metals and pesticide residues in Chinese medicinal materials have came out, the quality of Chinese medicinal materials has becoming paid more and more attention. The contents of harmful elements, pesticide residues and microorganism have become an important cause of serious influence on the export of Chinese medicinal materials and the modernization of traditional Chinese medicine (Iavicoli et al., 2009). Therefore, accurately detecting and limiting the amount of harmful substances such as heavy metals and pesticide residues is the key to ensure the safety of medication and to promote the internationalization of Chinese medicine (Efferth and Kaina, 2011). 
At present, the most toxic heavy metals are arsenic, cadmium, mercury and lead in environmental pollution, food safety and quality control of Chinese medicinal materials. However, heavy metals are parts of the natural environment. They are found in air, water and soil. In the process of Chinese herbal medicine, heavy metals can enter the medicinal materials through their growth environment, and then lead to heavy metal pollution through biological enrichment. The heavy metals in deer products are mainly derived from feeds which are fed, obviously this problem needs to be paid more attention during the processing and production, but it is often unavoidable. In addition, the production and processing of Chinese medicine preparation, the transportation and storage processing could also be polluted, these problems are accumulating and cause the heavy metal pollution of Chinese medicinal materials aggravating rapidly.

Pesticide residues, among the other potentially toxic compounds can be found in velvet antlers. According to the research status in recent years, pesticide residues in Chinese herbal medicines are universal (Kang et al., 2016; Yang et al., 2013), and organochlorine pesticide residues occupy a large proportion. The use of OCPs as insecticides and biocides has been widespread in agriculture and public health since the 1940s, and most of OCPs are resistant to photochemical, biological and chemical degradation for a long period of time (Yohannes et al., 2014). They persist in various media and some can be transported over long distances to regions where they have never been used. The use of most OCPs is now prohibited in China, but their low biodegradability means that they can still be detected in the environment (BarriadaPereira et al., 2003). The nature drugs from animal body may also be polluted in the process of formation, such as exposing to pesticides and other routes.

Moreover, Chinese herbal medicines may also be exposed to pesticides and contaminated during transportation, storage and processing (Ting et al., 2013). In addition, the pesticide residues in Chinese medicinal materials are likely to be enriched in the traditional Chinese medicine preparation by processing. Which are easily accumulated in the body by patients already infirm, posing a threat to drug safety. Therefore, the determination of pesticide residues has been included in the Chinese medicine inspection methods and quality standards formulated by WHO.

Velvet antler as the animal medicine is a kind of immature horn of most male deer family, which is widely distributed all over the world. China is one of the largest amount of numbers and species of deers, including Sika deer, Wapiti, elk and so on. Velvet antler is the only regenerable mammalian organ ( $\mathrm{Li}$ et al., 2014, 2016). It has special structural features, grows periodically and falls off each year, leaving no scars on the wound, the growth rate is very fast, reaching 1-2 cm per day. As a TCM, the pharmacological effects of velvet antler are enduring, which frequently performed to prevent and treat of osteoporosis (Tseng et al., 2014; Zhang et al., 2013), promoted cell proliferation (Xiao et al., 2017), repaired liver damage (Chunhua et al., 2017), antifatigue (Jang et al., 2014), anti-oxidation (Chunhui et al., 2017), anti-inflammatory (Ma et al., 2017; Lee et al., 2015) and showing other pharmacological activities. The composition of antler is extremely complex, the quality of different types of antler can be wildly different. In general, it can be divided into inorganic elements, organic components and bioactive ingredients.

The processing of velvet antler is according to the needs of Chinese medicine and pharmacy, putting dried velvet antler into Chinese Herbal Slices or other forms, for clinical use or variety of dosage forms. The Chinese Pharmacopoeia records two types of processing methods for velvet antler, "powder of velvet antler" and "tablets of velvet 
antler". Take the velvet antler, lick the hair, scrape it, smash it into pieces, grind it into fine powder, then get the powder of velvet antler. The processing of tablets of velvet antler is more complicated: Take the velvet antler, lick the hair, scrape it, and wrap the body with a cloth belt, injecting hot white spirit from the small hole in the wound surface, continue to add spirit, until the run through or the liquor is slightly steamed, cross-cut, flattened and dried (China Pharmacopoeia Committee, 2015). The velvet antler is transected and the transverse section is divided into skin layer, interstitial layer and medulla layer from the outside to the inside. According to the industry standard NY/T1162-2006 promulgated by the Ministry of Agriculture, the velvet pieces made from the tip to the base can be divided into four parts: wax piece, powder piece, yarn piece and bone piece.

At present, the main extraction methods used in the analysis of pesticide residues are: ultrasonic extraction, microwave assisted extraction, supercritical fluid extraction, solid phase extraction, solid phase microextraction, accelerated solvent extraction, liquid phase microextraction, QuEChERS and so on. Among the above, QuEChERS is a novel sample preparation methodology for pesticide multiresidue analysis which was developed between 2000 and 2002 and firstly reported in 2003 (Anastassiades et al., 2003). Although it is a very new method, it has already been widely accepted by pesticide residue analysts in the international community, and a lot of publications already deal with this method in its original form or variations of it (Hu et al., 2012). QuEChERS has been validated for the extraction of OCPs in completely different matrices of TCM (Xu et al., 2011).

In order to solve the problem of quality and safety in the development of Chinese medicinal materials, the new technology of detection of pesticide residues, such as modern spectral analysis, chromatography analysis, spectrum and chromatography, is rapidly developing (Kong et al., 2015; Tadeo et al., 2012). The commonly used methods are GC, gas chromatography-mass spectrometry, high performance liquid chromatography, liquid chromatography mass spectrometry and so on. Among which, GC has become one of the most important analysis methods in agricultural residue detection because of its good stability, high sensitivity, good selectivity and ability to separate a variety of substances at the same time. GC can be used to meet the detection requirements of different kinds of pesticides by selecting different detectors. It is often used to detect the pesticide residues with small relative molecular weight, low boiling point and good thermal stability. Because of the content of heavy metals in Chinese herbal medicines is generally low, it is necessary to select suitable analytical instruments and methods for testing. The ICP-MS is characterized by high sensitivity, high accuracy, low detection line, rapid analysis, and simultaneous determination of various elements (Jiang et al., 2014). It is the most effective method of elemental analysis recognized currently. It has been included in the Chinese Pharmacopoeia as one of the methods for determining lead, cadmium, arsenic, mercury and copper in Chinese herbal medicines (China Pharmacopoeia Committee, 2015).

\section{Materials}

\section{Sampling}

In order to ensure the current pollution situation, samples were chosen: New Zealand plum velvet antler powder, red powder, wax tablets, Jilin sika deer antler red powder, yellow powder, wax tablets, Jilin red deer pilose antler powder tablets, sand tablets, wax 
tablets both are purchased from a farm in Shuangyang District, Changchun City, Jilin Province, China. The feeding method is captive. (Fig. 1). The fodder are mainly corn, soybean and bean cake, and the roughage are silage corn stalk, grass and leaves. All the samples were ground and passed through 80 -mesh sieve and stored at $-20{ }^{\circ} \mathrm{C}$ prior analyses.

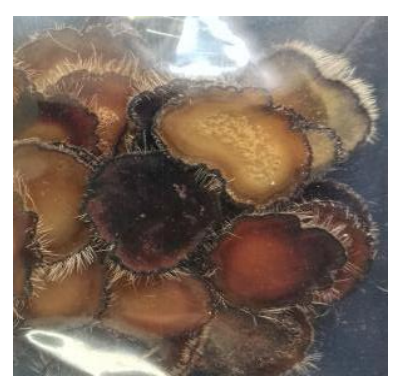

$\mathbf{A}$

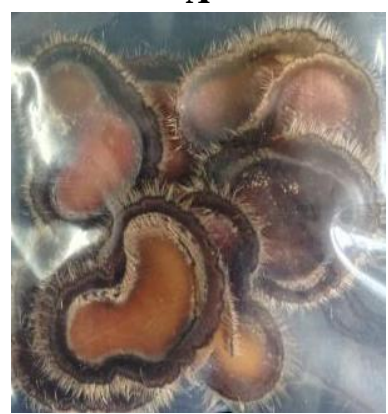

$\mathbf{D}$

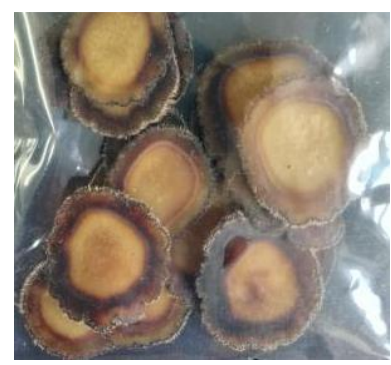

$\mathbf{G}$

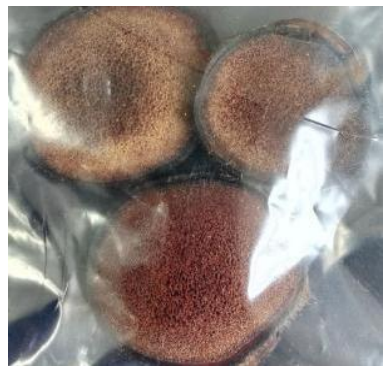

B

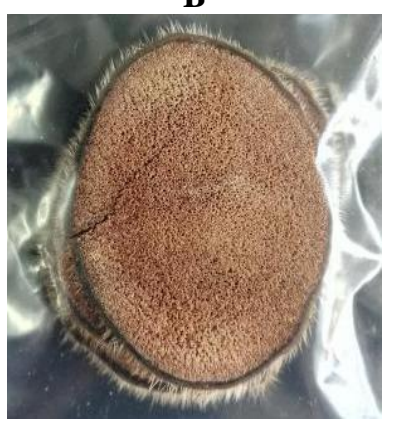

$\mathbf{E}$

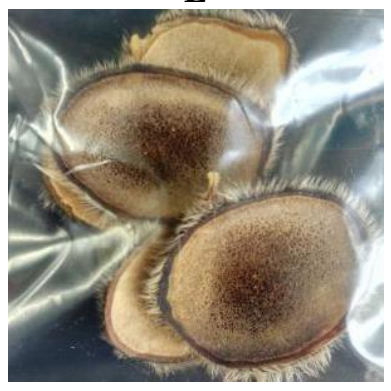

H

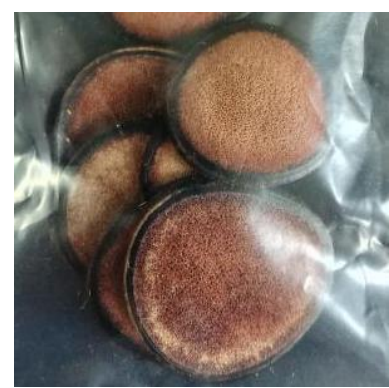

$\mathbf{C}$

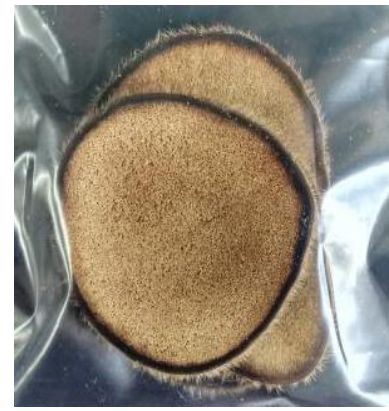

$\mathbf{F}$

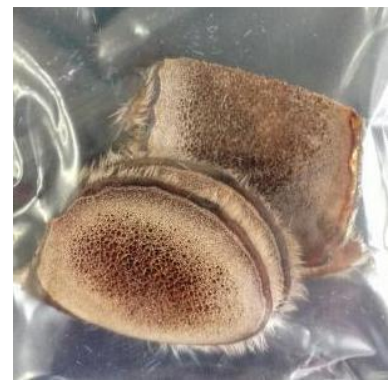

I

Figure 1. Different varieties of velvet antlers. A: New Zealand sika deer antler wax tablets. B: New Zealand sika deer antler red powder. C: New Zealand sika deer antler powder. D: Jilin sika deer antler wax tablets. E: Jilin sika deer antler red powder. F: Jilin sika deer antler yellow powder. G: Jilin red deer pilose antler powder wax tablets. H: Jilin red deer pilose antler powder tablets. I: Jilin red deer pilose antler sand tablets

\section{Experimental method}

\section{Pesticide analysis by $G C$}

\section{Preparation of standard solution}

All OCP standards $(\alpha$-BHC, $\beta$-BHC, $\gamma$-BHC, $\delta$-BHC, o, p'-DDD, p, p'-DDD, o, p'DDT, p, p'-DDT, Pentachloronitrobenzene (PNCB) were purchased from the National Standards Research Center. A mixed stock solution was prepared by dissolving exact amounts of powdered samples in mixture of methanol and toluene $(3: 1, \mathrm{v} / \mathrm{v})$ at a concentration of $100 \mathrm{ng} / \mathrm{mL}$, and then diluted to a mixed standard solution with a 
concentration of $10 \mathrm{ng} / \mathrm{mL}$. A series of standard solutions with concentrations of 1,5 , 10,50 , and $100 \mathrm{ng} / \mathrm{mL}$ were prepared and the calibration curves were established after measurement.

\section{Extraction and clean-up}

Extraction and clean-up were carried out according to the QuEChERS method (Anastassiades et al., 2007). Nine samples were separately added to liquid nitrogen, ground and passed through a 80 -mesh sieve. $0.5 \mathrm{~g}$ of sample was weighed into the $15 \mathrm{~mL}$ centrifuge tubes. The main extraction involved the addition of $1.5 \mathrm{~g}$ of sodium acetate, $10 \mathrm{~mL}$ of acidum aceticum-water-acetonitrile $(1: 4: 95, \mathrm{v} / \mathrm{v})$. The tube was closed and shaken vigorously by hand for $2 \mathrm{~min}$. Then, $1.5 \mathrm{~g}$ of anhydrous $\mathrm{MgSO}_{4}$ (burned in a high-temperature muffle furnace for $4 \mathrm{~h}$ ) was added to the suspension. The tube was closed, shaken vigorously by hand for $2 \mathrm{~min}$, and centrifuged for $5 \mathrm{~min}$ at $3000 \mathrm{r} / \mathrm{min}$.

For clean-up, $1 \mathrm{~mL}$ of the upper organic phase was transferred into a $2-\mathrm{mL}$ centrifugation tube already containing $25 \mathrm{mg}$ PSA, $25 \mathrm{mg}$ GCB and $150 \mathrm{mg}$ anhydrous $\mathrm{MgSO}_{4}$. The tube was closed, shaken vigorously by hand for $2 \mathrm{~min}$, and centrifuged for $5 \mathrm{~min}$ at $12000 \mathrm{r} / \mathrm{min}$. An upper organic phase was taken and concentrated by nitrogen to $200 \mu \mathrm{L}$ for injection.

\section{GC analyses}

The measurement conditions were as follows: TG-5 quartz capillary column; The column temperature was maintained at $120{ }^{\circ} \mathrm{C}$ for $1 \mathrm{~min}$, and then ramped at $6{ }^{\circ} \mathrm{C} \mathrm{min}^{-1}$ up to $180{ }^{\circ} \mathrm{C}$ and kept for $2 \mathrm{~min}$, then at $10^{\circ} \mathrm{C} \min ^{-1}$ up to $280{ }^{\circ} \mathrm{C}$ and kept for $2 \mathrm{~min}$; Detector temperature: $300{ }^{\circ} \mathrm{C}$; Injector temperature: $230{ }^{\circ} \mathrm{C}$; Carrier gas: $\mathrm{N}_{2}$; Flow rate $40 \mathrm{~mL} / \mathrm{min}$; The sample injection volume was $1 \mu \mathrm{L}$, no splitting and external standard method for quantification.

\section{Chemical analysis of the mineral composition}

\section{Preparation of standard solution}

The elements standard solutions were prepared by $5 \%$ nitric acid solution diluting stock solution of $1000 \mu \mathrm{g} / \mathrm{mL} \mathrm{As}, \mathrm{Cd}, \mathrm{Pb}, \mathrm{Hg}$ and $\mathrm{Cu}$ (purchased from National Nonferrous Metals and Electronic Materials Analysis and Testing Center) to prepare a mixed standard stock solution with a concentration of $1000 \mu \mathrm{g} / \mathrm{L}$. The mixture was further diluted to a mixed standard solution of $0.5,1,2,10,20,50 \mu \mathrm{g} / \mathrm{L}$ and stored at 4 ${ }^{\circ} \mathrm{C}$. Then the calibration curves were established after measurement.

\section{Extraction}

The heavy metals including $\mathrm{As}, \mathrm{Cd}, \mathrm{Pb}, \mathrm{Hg}$ and $\mathrm{Cu}$ were analyzed by using ICP-MS. Before the analysis, samples were digested by using a microwave digestion system. Nine samples were separately added to liquid nitrogen, ground and passed through 80mesh sieve. The sample was accurately weighed $0.5 \mathrm{~g}$, placed in a microwave digestion tank and added $8 \mathrm{~mL}$ of nitric acid. The digestion procedures were carried out in a microwave oven according to the digestion setting (Table 1). After the temperature of the digestion solution dropped below $60^{\circ} \mathrm{C}$, the digestion tank is taken out. The samples were cooled to room temperature and ultrapure water was added to a total volume of $25 \mathrm{~mL}$. The samples were stored at $4{ }^{\circ} \mathrm{C}$ before analysis. 


\section{ICP-MS analyses}

The measurement conditions were: Plasma gas flow: $15.0 \mathrm{~L} / \mathrm{min}$; Spray chamber temperature: $2{ }^{\circ} \mathrm{C}$; Auxiliary gas flow: $0.85 \mathrm{~L} / \mathrm{min}$; He gas flow: $5 \mathrm{~mL} / \mathrm{min}$; Carrier gas flow: $1 \mathrm{~L} / \mathrm{min}$; RF power: $1450 \mathrm{~W}$; Data sampling mode: peak capture mode; Sampling depth: $8 \mathrm{~mm}$; Number of sweeps: 100 times.

Table 1. Microwave digestion procedure

\begin{tabular}{c|c|c|c}
\hline Step & Set temperature $\left({ }^{\circ} \mathbf{C}\right)$ & Heating time $(\mathbf{m i n})$ & Duration $(\mathbf{m i n})$ \\
\hline 1 & 130 & 4 & 5 \\
2 & 160 & 4 & 10 \\
3 & 210 & & 15 \\
\hline
\end{tabular}

\section{Statistical analysis}

All data are expressed as average value of concentration and standard deviation. Descriptive statistics of the determined results were calculated by using MS Office Excel software, and the Excel add-in "Data Analysis suite" was applied for the linear regression analysis.

\section{Results and discussion}

\section{Pesticide residue test results}

Figure 2 shows typical gas chromatograms of standards for the nine pesticides. The calibration curves were obtained using the linear least squares regression procedure of the peak area versus the concentration. The results show that the concentration has a good linear relationship with the peak area, and the linearity is greater than 0.99 . The calibration curves were enough for the detection OCPs in samples. The nine samples were extracted, clean-up and measured according to the method described in the section "Pesticide analysis by GC", while the OCPs were well separated (Fig. 2).

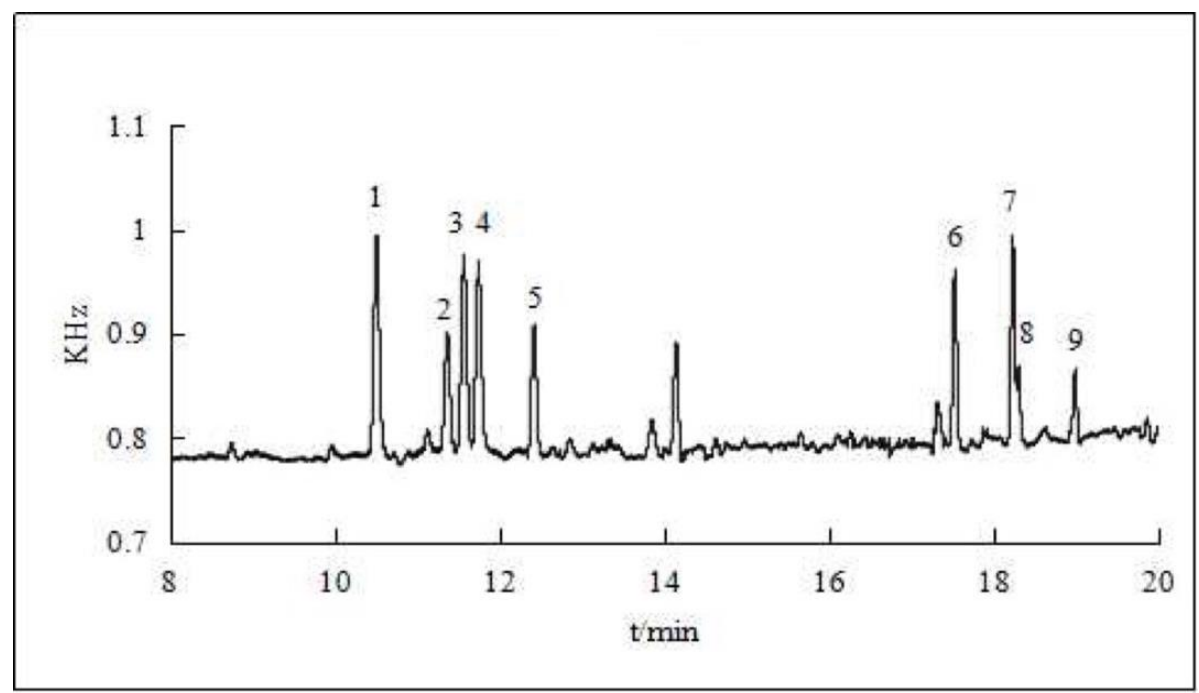

Figure 2. Chromatogram of organochlorine pesticides standards. 1. $\alpha$-BHC; $2 . \beta$-BHC; 3. $\gamma$ $B H C$; 4. PCNB; 5. $\delta$-BHC; 6. o, p'-DDD; 7. p, p'-DDD; 8. o, p'-DDT; 9. p, p'-DDT 


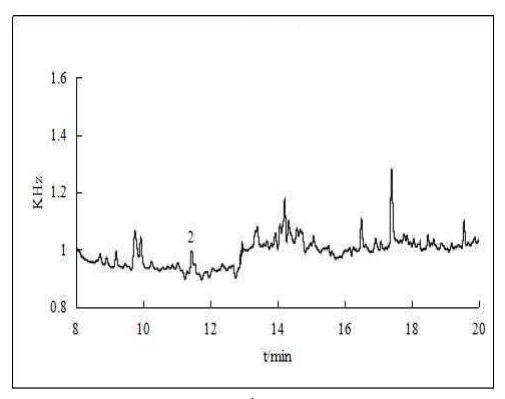

A

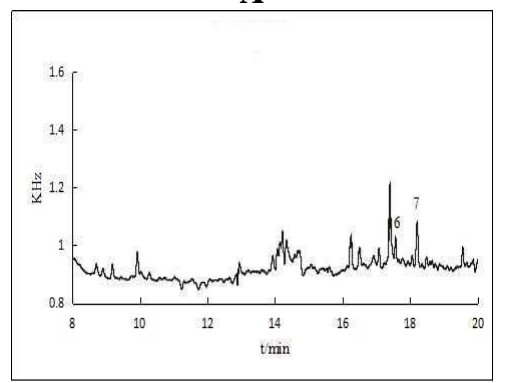

D

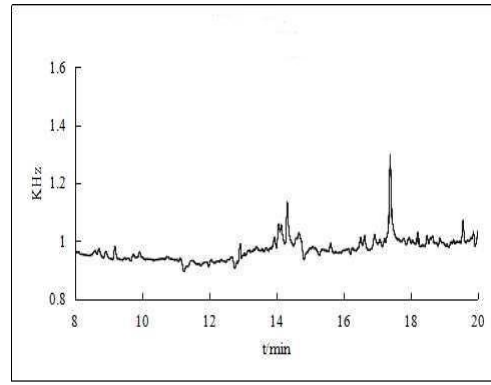

G

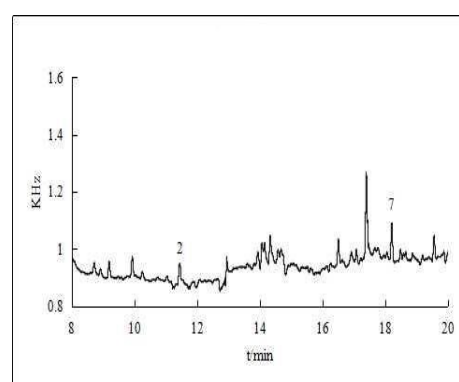

B

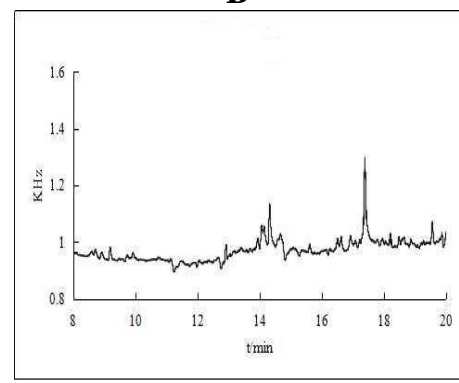

$\mathbf{E}$

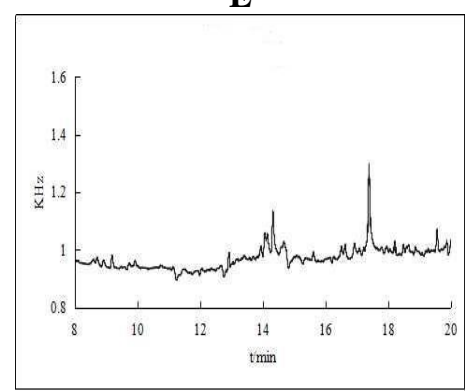

H

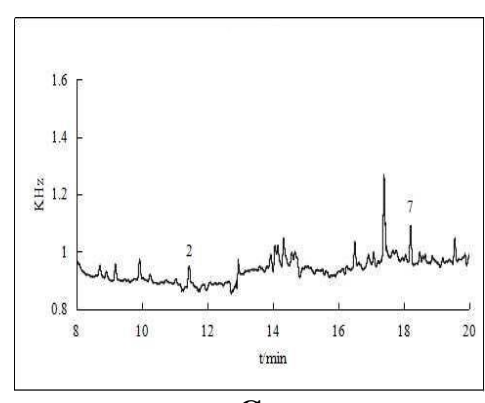

C

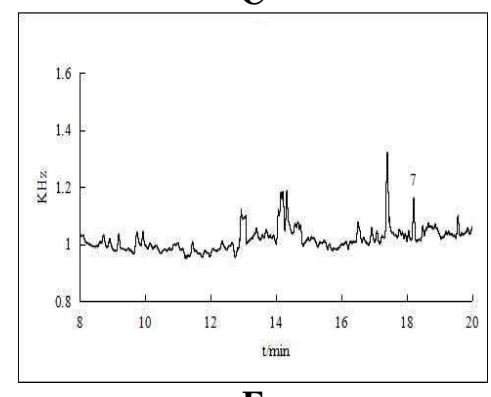

$\mathbf{F}$

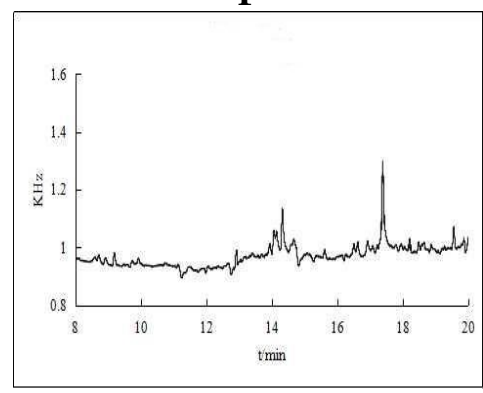

I

Figure 3. Chromatogram of organochlorine pesticides of velvet antlers. A: New Zealand sika deer antler wax tablets. B: New Zealand sika deer antler red powder. C: New Zealand sika deer antler powder. D: Jilin sika deer antler wax tablets. E: Jilin sika deer antler red powder. F: Jilin sika deer antler yellow powder. G: Jilin red deer pilose antler powder wax tablets. H: Jilin red deer pilose antler powder tablets. I: Jilin red deer pilose antler sand tablets

Nine velvet samples were quantified according to the peak area external standard method to calculate the residual amount of various organochlorine pesticides in the sample (Fig. 3). In this work, Table 2 shows that the concentrations of contaminants detected in the nine samples did not exceed the maximum allowable residue limits (MRLs) which specified in the Chinese Pharmacopoeia (total BHC $<200 \mu \mathrm{g} / \mathrm{kg}$ and total DDT < $200 \mu \mathrm{g} / \mathrm{kg}$ ) (Chinese Pharmacopoeia Commission, 2015).

The residual levels of some OCPs in environment seem to remaining approximately twenty years at least. In general, plant medicinal materials are in direct contact with the soil, so the pesticide content of botanicals is relatively high. During this study, the levels of OCPs in the nine samples were found to be in accordance with Chinese Pharmacopoeia standards. However, there is still a certain amount of pesticide residues in the antler, which indicates that the possibility of pesticide residues in animal drugs, and should be tested before giving to patients to ensure the medication safety. In addition, data support is provided to continually correct reasonable maximum residue limits (MRLs). 
Table 2. The content of organochlorine pesticides in different kinds of velvet antlers $(n=3)$

\begin{tabular}{c|c|c|c|c}
\hline \multirow{2}{*}{ Antler species } & \multicolumn{4}{|c}{ Concentration $(\boldsymbol{\mu g} / \mathbf{k g})$} \\
\cline { 2 - 5 } & $\boldsymbol{\beta}$-BHC & $\boldsymbol{\delta}$-BHC & $\mathbf{o ,} \mathbf{p}$-DDD & $\mathbf{p}, \mathbf{p}$-DDD \\
\hline Jilin plum velvet wax tablets & - & - & $3.87 \pm 0.32$ & $11.60 \pm 1.22$ \\
Jilin plum antler yellow powder & - & - & - & $10.08 \pm 0.84$ \\
Jilin plum antler red powder & - & - & - & - \\
Jilin horse velvet wax tablets & - & - & - & $11.40 \pm 0.95$ \\
Jilin horse antler powder tablets & $2.70 \pm 0.15$ & $3.60 \pm 0.47$ & - & - \\
Jilin horse velvet sand & - & - & - & - \\
New Zealand sika antler wax tablets & $2.90 \pm 0.14$ & - & - & - \\
New Zealand sika antler powder & $4.95 \pm 0.29$ & - & - & $10.56 \pm 1.13$ \\
New Zealand plum antler red powder & - & - & $4.00 \pm 0.54$ & - \\
\hline
\end{tabular}

\section{Heavy metal test results}

${ }^{63} \mathrm{Cu}$ and ${ }^{75} \mathrm{As}$ with ${ }^{72} \mathrm{Ge}$ as the internal standard, ${ }^{111} \mathrm{Cd}$ with ${ }^{115} \mathrm{In}$ as the internal standard, ${ }^{201} \mathrm{Hg}$ and ${ }^{208} \mathrm{~Pb}$ with ${ }^{209} \mathrm{Bi}$ as the internal standard. During the measurement, the internal standard samples tube were always inserted into the internal standard solution, and the samples tube of the instrument were inserted into the mixed standard solution with a concentration of $0.5,1,2,10,20,50 \mu \mathrm{g} / \mathrm{L}$ and nine velvet samples for measurement. As Table 3 showed that the calibration curves of the five heavy metal elements have a good linear relationship, and the correlation coefficients (r) were all above 0.99 .

Table 3. Standard curves and linear relations

\begin{tabular}{c|c|c}
\hline Measuring element & Regression equation & r \\
\hline $\mathrm{Cu}$ & $\mathrm{y}=3.2998 \mathrm{x}-0.8663$ & 0.9968 \\
$\mathrm{As}$ & $\mathrm{y}=0.0377 \mathrm{x}+0.0113$ & 0.9995 \\
$\mathrm{Cd}$ & $\mathrm{y}=0.0064 \mathrm{x}+0.0167$ & 0.9992 \\
$\mathrm{Hg}$ & $\mathrm{y}=0.0024 \mathrm{x}-0.0013$ & 0.9998 \\
$\mathrm{~Pb}$ & $\mathrm{y}=0.0088 \mathrm{x}-0.0034$ & 0.9996 \\
\hline
\end{tabular}

The results of determination of heavy metals were shown in Table 4, which can be seen that the nine velvet samples contain a certain amount of heavy metals and the content of $\mathrm{Cu}$ was relatively high. In addition, the heavy metal content of the wax sheet was higher than other parts of the velvet antler. In particular, Jilin plum velvet wax tablets have the highest content of heavy metals.

This study revealed that the contents of heavy metals from nine samples are in line with the permissible limits, but the level of $\mathrm{Cu}$ in the samples was generally higher, and the heavy metals remaining of the wax tablets were higher than the other parts of the antler. Food chain in the ecosystem is a process, which stored chemical energy in organic matter conducting layer by layer. The absorption and enrichment of heavy metal in CMs are the important factors causing the potential quality problems of clinical application. In the natural world, green plants are almost at the end of the bio-chain. 
Heavy metal elements are absorbed by green plants and transported step by step along the chain, enforce accumulating and generating bio-magnification effects. Compared with green plants, animals are at the top of the bio-chain, which is more likely to be contaminated by heavy metals and harmful elements. The wax is the tip of the antler, thus the accumulation of heavy metals and harmful elements is higher. From this point of view, comprehensive and objective evaluation of the content of heavy metals in animal drugs can provide realistic data support for the safety of medication.

Table 4. The content of 5 kinds of heavy metals in velvet antlers $(n=3)$

\begin{tabular}{c|c|c|c|c|c}
\hline Antler species & \multicolumn{5}{|c}{ Concentration $(\mathbf{m g} / \mathbf{k g})$} \\
\hline Limit of detection & $\mathbf{C u}$ & $\mathbf{A s}$ & $\mathbf{C d}$ & $\mathbf{H g}$ & $\mathbf{P b}$ \\
\hline Jilin plum velvet wax tablets & 20 & 5 & 1 & 1 & 10 \\
Jilin plum antler red powder & $2.577 \pm 0.18$ & $0.200 \pm 0.014$ & $0.011 \pm 0.005$ & $0.014 \pm 0.007$ & $0.688 \pm 0.074$ \\
Jilin plum antler yellow powder & $2.675 \pm 0.16$ & $0.103 \pm 0.025$ & $0.003 \pm 0.0007$ & $0.022 \pm 0.014$ & $0.372 \pm 0.032$ \\
Jilin horse velvet wax tablets & $5.065 \pm 0.22$ & $0.092 \pm 0.01$ & $0.001 \pm 0.0003$ & $0.008 \pm 0.002$ & $0.098 \pm 0.002$ \\
Jilin horse velvet sand & $1.033 \pm 0.092$ & $0.117 \pm 0.011$ & $0.001 \pm 0.00$ & $0.010 \pm 0.001$ & $0.588 \pm 0.018$ \\
Jilin horse antler powder tablets & $0.905 \pm 0.06$ & $0.062 \pm 0.017$ & $0.001 \pm 0.00$ & $0.010 \pm 0.001$ & $0.624 \pm 0.049$ \\
New Zealand sika antler wax tablets & $4.428 \pm 0.11$ & $0.109 \pm 0.025$ & $0.003 \pm 0.0011$ & $0.011 \pm 0.005$ & $0.104 \pm 0.019$ \\
New Zealand sika antler powder & $2.197 \pm 0.15$ & $0.041 \pm 0.009$ & $0.005 \pm 0.002$ & $0.113 \pm 0.025$ & $0.116 \pm 0.16$ \\
New Zealand plum antler red powder & $2.573 \pm 0.17$ & $0.172 \pm 0.067$ & $0.012 \pm 0.003$ & $0.275 \pm 0.035$ & $0.279 \pm 0.008$ \\
\hline
\end{tabular}

Interestingly, studies have shown that there are excessive $\mathrm{Cu}$ and $\mathrm{Cd}$ contents in corn and soybean crops in Jilin Province (Liang et al., 2011). Therefore, we have reasons to suspect that the presence of heavy metals in velvet antlers may be enriched by food, and the food pathway only affects the content of heavy metals in antler. It could be related to the process of transportation and storage, so the reasons for the existence of heavy metals in antler must be further investigated to ensure the medication safety.

\section{Conclusions}

As a natural medicine, TCM has been favoured by patients because of its less side effects, good curative efficiency and medicine safety, which has been recognized and accepted by the international community gradually. TCM is a group of special products used by doctors to prevent and treat diseases, it would be rare for such plants or animal can use both as food and medicine to produce toxic effects on human body. It is the uniqueness of traditional Chinese medicine. However, due to the possibility that CMs may be contaminated by toxic and harmful substances during planting, processing, storage and so on, these pollution poses a certain threat to human health, which in turn affects the safety of its use. Animal medicine refers to the whole or parts of the body, the physiological or pathological product of the animal, the processed products, and the like, has taken a place for thousands of years. "Shen Nong's Herbal Classic" contains 365 kinds of drugs, including 67 kinds of animal drugs, and the number of animal drugs in the "Compendium of Materia Medica" increased to 461 kinds. Animal medicine has the characteristics of strong activity and high curative effect, which is an indispensable component of TCM. Nowadays, there are many pharmacological studies on animal 
drugs, but studies on safety issues such as residues of harmful substances are rare. Only a few analytical methods for determining pesticide residues in TCM have been reported.

Velvet antler is one of the representative animal drugs in TCM. Chinese deer industry has made great progress after continuous development. However, problems such as lack of talents, backward technology, extensive management, new technologies and methods have not been well promoted and applied in production practice are still exist. The world's leading exporters of velvet antler are New Zealand, Canada and Russia, of which New Zealand deer Antler has the greatest impact on Chinese antler industry.

The results show that although several OCPs detected in this subject have been banned for a while, some pesticide residues still can be found in velvet antlers. The content of heavy metal $\mathrm{Cu}$ in velvet antler is high, meanwhile the heavy metal pollution in the part of wax sheets is the worst, and provide a reference data for the further studies focused on the safety of herbal preparations. In addition, the source of heavy metal and pesticide pollution in antler is likely to be related to the management of farms, the processing of feed, medicine, transportation, storage and so on. Pharmacopoeia has only specified the source and type of deer antler, the method of identification, as well as the production methods of antler slices and powder. But the specification and quality description of the products of deer antler is too macroscopic; the identification method is too simple and not specific. Obviously, antler as traditional Chinese medicine needs to be further developed, clear breeding and regulatory standards should be established as soon as possible. Improving the more targeted analytical methods are useful for developing realistic MRLs and other regulatory guidelines for managing pesticide heavy metal residues in TCM products.

Acknowledgements. The English titles of books and the papers that are published in Chinese are translations made by the authors. This work was supported by the National Natural Science Foundation of China (grant no. 81503177 and 81573999), and the Fundamental Research Funds for the Central Universities (DUT19LK57).

\section{REFERENCES}

[1] Anastassiades, M., Lehotay, S. J., Stajnbaher, D., Schenck, F. J. (2003): Fast and easy multiresidue method employing acetonitrile extraction/partitioning and "dispersive solidphase extraction" for the determination of pesticide residues in produce. - J AOAC Int 86(2): 412-31.

[2] Anastassiades, M., Tasdelen, B., Scherbaum, E., Stajnbaher, D. (2007): Recent Developments in QuEChERS Methodology for Pesticide Multiresidue Analysis. - In: Ohkawa, H., Miyagawa, H., Lee, P. W. (eds.) Pesticide Chemistry: Crop Protection, Public Health, Environmental Safety. Wiley-VCH, Weinheim.

[3] Barriada-Pereira, M., Concha-Grana, E., Gonzalez-Castro, M. J., Muniategui-Lorenzo, S., Lopez-Mahia, P., Prada-Rodriguez, D., Fernandez-Fernandez, E. (2003): Microwaveassisted extraction versus Soxhlet extraction in the analysis of 21 organochlorine pesticides in plants. - J Chromatogr A 1008(1): 115-22.

[4] China Pharmacopoeia Committee (2015): Chinese Pharmacopoeia. - China Medical Science and Technology Press, Beijing.

[5] Chunhua, M., Hongyan, L. (2017): Protective effect of pilose antler peptide on carbon tetrachloride-induced hepatotoxicity in mice. - International Journal of Biological Macromolecules 99(6): 648-654. 
[6] Chunhui, Y., Wenjun, C., Hui, W., Liquan, S., Changwei, Z., Tianzhu, Z. (2017): Pilose antler peptide protects osteoblasts from inflammatory and oxidative injury through EGF/EGFR signaling. - Int J Biol Macromol 99: 15-20.

[7] Efferth, T., Kaina, B. (2011): Toxicities by herbal medicines with emphasis to traditional Chinese medicine. - Curr Drug Metab 12(10): 989-96.

[8] Hu, Y., Wan, L., Zhang, J., Yang, F., Cao, J. (2012): Rapid determination of pesticide residues in Chinese materia medica using QuEChERS sample preparation followed by gas chromatography-mass spectrometry. - Acta Pharmaceutica Sinica B 2(3): 286-293.

[9] Huie, C. W. (2002): A review of modern sample-preparation techniques for the extraction and analysis of medicinal plants. - Anal Bioanal Chem 373(1-2): 23-30.

[10] Iavicoli, I., Fontana, L., Bergamaschi, A. (2009): The effects of metals as endocrine disruptors. - Journal of Toxicology and Environmental Health, Part B 12(3): 206-223.

[11] Jang, S., Park, E. D., Suh, H. J., Lee, S. H., Kim, J. S., Park, Y. (2014): Enhancement of exercise endurance capacity by fermented deer antler in BALB/c mice. - Biosci Biotechnol Biochem 78(10): 1716-22.

[12] Jiang, J., Feng, L., Li, J., Sun, E., Ding, S. M., Jia, X. B. (2014): Multielemental composition of suet oil based on quantification by ultrawave/ICP-MS coupled with chemometric analysis. - Molecules 19(4): 4452-65.

[13] Kang, C. Z., Guo, L. P., Zhou, T., Zhao, D., Kang, L. P., He, Y. L., Wang, S., Zhou, L. Y. (2016): Discussion on present situation of study on pesticide residues in Chinese herbal medicines. - Zhongguo Zhong Yao Za Zhi 41(2): 155-159.

[14] Kong, L., Zhang, Y., Gu, L., He, B., Hu, J., Pang, H., Qin, G. (2015): Research Progress of Traditional Chinese Medicine Pesticide Residues. - Chinese Journal of Experimental Traditional Medical Formulae 21(21): 231-234.

[15] Lee, S. H., Yang, H. W., Ding, Y., Wang, Y., Jeon, Y. J., Moon, S. H., Jeon, B. T. (2015): Anti-inflammatory effects of enzymatic hydrolysates of velvet antler in RAW 264.7 cells in vitro and zebrafish model. - Excli J 14: 1122-32.

[16] Li, C., Chu, W. (2016): The regenerating antler blastema: the derivative of stem cells resident in a pedicle stump. - Front Biosci (Landmark Ed) 21(3): 455-467.

[17] Li, C., Zhao, H., Liu, Z., McMahon, C. (2014): Deer antler-a novel model for studying organ regeneration in mammals. - Int J Biochem Cell Biol.56: 111-122.

[18] Liang, X. H., Cao, T. H., Zhang, L., Yu, L., Liu, X. G. (2011): Content of heavy metals in farmland soil and accumulation in crops in Jilin province. - Journal of Jilin Agricultural Sciences 36(6): 59-62.

[19] Ma, C., Long, H., Yang, C., Cai, W., Zhang, T., Zhao, W. (2017): Anti-inflammatory role of pilose antler peptide in LPS-induced lung injury. - Inflammation 40(3): 904-912.

[20] Tadeo, J. L., Perez, R. A., Albero, B., Garcia-Valcarcel, A. I., Sanchez-Brunete, C. (2012): Review of sample preparation techniques for the analysis of pesticide residues in soil. - J AOAC Int 95(5): 1258-71.

[21] Ting, A., Chow, Y., Tan, W. (2013): Microbial and heavy metal contamination in commonly consumed traditional Chinese herbal medicines. - J Tradit Chin Med 33(1): $119-24$.

[22] Tseng, S. H., Sung, C. H., Chen, L. G., Lai, Y. J., Chang, W. S., Sung, H. C., Wang, C. C. (2014): Comparison of chemical compositions and osteoprotective effects of different sections of velvet antler. - J Ethnopharmacol 51(1): 352-60.

[23] Xiao, X., Li, L., Xu, S., Mao, M., Pan, R., Li, Y., Wu, J., Huang, L., Zheng, X. (2017): Evaluation of velvet antler total protein effect on bone marrow-derived endothelial progenitor cells. - Mol Med Rep 16(3): 3161-3168.

[24] Xu, R., Wu, J., Liu, Y., Zhao, R., Chen, B., Yang, M., Chen, J. (2011): Analysis of pesticide residues using the Quick Easy Cheap Effective Rugged and Safe (QuEChERS) pesticide multiresidue method in traditional Chinese medicine by gas chromatography with electron capture detection. - Chemosphere 84(7): 908-912. 
[25] Yang, Y. H., Dou, X. W., Kong, W. J., Yang, M. H., Chen, S. L., Xiao, Q. (2013): Status of pesticide registration and residue analysis for traditional Chinese medicine in China. Zhongguo Zhong Yao Za Zhi 38(24): 4238-45.

[26] Yohannes, Y. B., Ikenaka, Y., Saengtienchai, A., Watanabe, K. P., Nakayama, S. M., Ishizuka, M. (2014): Concentrations and human health risk assessment of organochlorine pesticides in edible fish species from a Rift Valley lake - Lake Ziway, Ethiopia. Ecotoxicol Environ Saf 95-101.

[27] Zhang, L. Z., Xin, J. L., Zhang, X. P., Fu, Q., Zhang, Y., Zhou, Q. L. (2013): The antiosteoporotic effect of velvet antler polypeptides from Cervus elaphus Linnaeus in ovariectomized rats. - J Ethnopharmacol 150(1): 181-186. 